\title{
Development and Research on the Equipments Management Information System of Railway Enterprises
}

\author{
Lei Ma \\ I.T Department, China Academy of Railway Sciences \\ Beijing, China \\ malei2565@sina.com
}

\begin{abstract}
In this paper, the concept of domestic and foreign about equipments management in enterprises and information construction method was be fully concerned, combined with the actual manage situation of railway corporation and the railway transport enterprises, this paper puts forward the construction ideas and goals of the equipments management system in railway enterprises. Meanwhile, this paper fully considering the business integration and information sharing between the system and ERP, OA and railway materials management information system, the concept of enterprise information construction and intensive management was be fully reflected.
\end{abstract}

Keywords-Railway Enterprises; Equipments Management; ERP; OA; RMMIS

\section{INTRODUCTION}

As a key for corporate internal management, equipment management is an important tool and means for enterprises' production, operation and routine work. It is not only essential material wealth for survival and development of enterprises, but also fundamental for enterprises to increase their economic benefits. Equipment management aims to guarantee efficient and safe operation of equipment within a long cycle by advanced means of management and effective management measures, in order to make sure that enterprises can gain higher economic benefits.

With the constant expansion of railway enterprises and extension of industry chains over the past years, there has been a greater amount of more diversified equipment with more complicated technical structures to be managed. To strengthen corporate equipment management and ensure supply of equipment necessary for scientific research experiments, test, development, production and construction, guarantee equipment quality and increase overall economic benefits, China Railway Corporation and railway transport enterprises have proposed higher requirements for scope and meticulousness of equipment management in succession.

Based on the management concept of full lifecycle of equipment, an integrated equipment management information system is constructed for railway enterprises by computer and Internet of Things (IoT) technologies to completely know about basic conditions and use of equipment, standardize and strengthen basic management and operation monitoring, in order to provide information for railway enterprises as basis for them to make scientific decisions about equipment management [1].

Meanwhile, this system is effectively integrated with corporate ERP (SAP) financial system, railway material management information system and OA system (Office Automatic) for the purpose of business collaboration and information interconnection among departments of an enterprise at all levels.

\section{BUSINESS ANALYSIS}

Full lifecycle management of equipment is divided into three phases, including early management, operation \& maintenance, and scrapping.

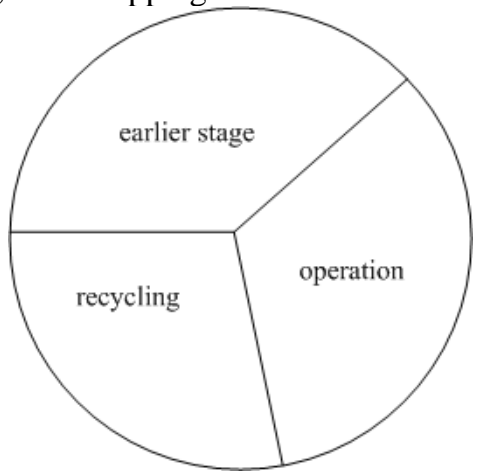

Figure 1. The Full lifecycle management of equipment

Early management mainly covers planning for equipment procurement, bidding, type selection, procurement, acceptance of incoming goods, installation and commissioning. In the phase of operation \& maintenance, the management mainly covers routine maintenance, inspection, monitoring, diagnosis, repair and updating of equipment, in an attempt to ensure equipment is often in good technical conditions during their operation. In the phase of scrapping, efforts are mainly made to scrap and recycle equipment which reaches the end of their service life, malfunctions frequently, requires much cost for repair and still fails to meet technical requirements after repair, to end the service of equipment.

\section{General System DeSIGN}

\section{A. The Technical Architecture}

A Browser/Server $(\mathrm{B} / \mathrm{S})$ architecture is developed by JAVA EE in JAVA, and Mysql is used as database. It is divided into four layers, including presentation layer, business logic layer, data access layer and data layer [3-4]. 


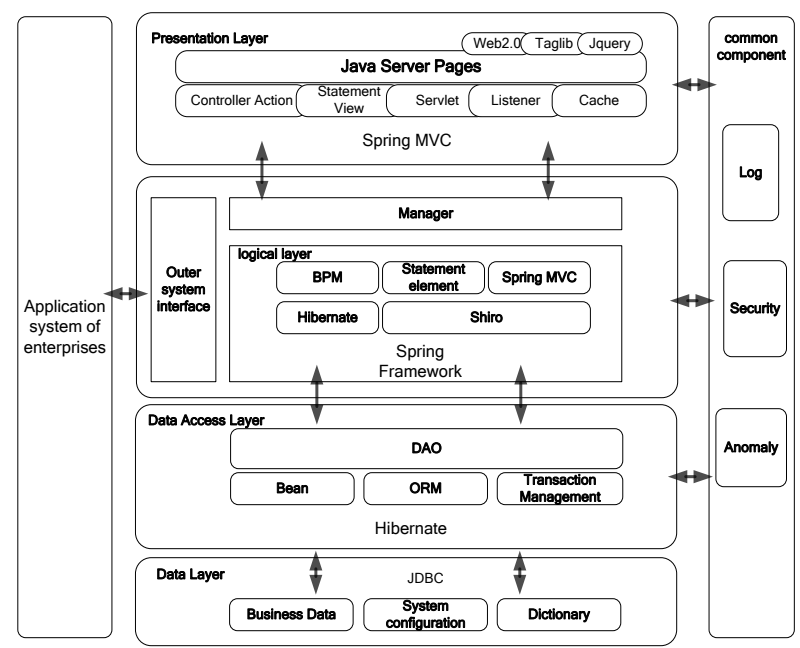

Figure 2. The technical architecture diagram of the system

\section{1) Presentation Layer}

As a layer for users' interactions with the system, presentation layer presents the information of business logic layer thoroughly from multiple perspectives to users. It makes management tools and platforms available to users of corporate equipment management at all levels for them to effectively process and analyze information of the business logic layer by comprehensive and integrated operations of functions like approval, query and statistics.

\section{2) Business Logic Layer}

As a part of the architecture that reflects the core value of a system, business logic layer focuses on system design related to needs for all-service equipment management. It provides workflow engines, report components and form templates that support high-level applications. On this layer, business integration and data transmission between this system and the external are realized through a uniform interface platform [5].

\section{3) Data Access Layer}

This layer includes centralized database, related local data interfaces of informatization systems, data interfaces of relevant external information systems and mechanisms for information sharing and exchange.

\section{4) Data Layer}

This layer is used for storing data about businesses, system configurations and basic data dictionaries.

\section{B. Functional Design of System}

\section{1) Equipment Management}

As a core module for dynamic business processing in the entire cycle of equipment management, equipment management mainly includes technical acceptance of equipment, creation of equipment cards, creation of machine accounts, modification of equipment cards, storage/use, appropriation, disassembly, scrapping, recycling and handling of variable businesses. It can solve problems concerning relationships between equipment and fixed assets, components and accessories, to lay a foundation for equipment operation, maintenance and repair.

\section{2) Operation Management}

Being responsible for maintaining information about routine operations of equipment, this module mainly covers failure records, regular inspection, maintenance and management of equipment. An application form for equipment repair may be automatically generated in the failure records while the equipment is maintained. The function of regular inspection is mainly responsible for making plans for equipment inspection and filling up actual inspection results. Warnings can be set for dates when equipment shall be delivered for inspection, so users can intuitively check information about different equipment to be inspected on the first page of the system, to guarantee prompt delivery for inspection and normal stable operations of equipment.

\section{3) Maintenance Management}

Designed for making plans for independent/external repair or maintenance and filling up actual repair or maintenance results, this module is closely connected with practical repair and maintenance services. By completely maintaining information about equipment repair and maintenance at different levels, including items, requirements, standards, charges and hours of repair and maintenance, it can effectively analyze causes of equipment failures and save repair and maintenance costs [6-7].

\section{4) Statistical Analysis}

In this module, the system mainly generates and exports related reports according to statistical requirements of the China Railway Corporation and enterprises at all levels for equipment. Besides, it can automatically calculate indexes such as equipment failure rate, breakdown rate and repair rate based on data about equipment failures and breakdown, to provide reliable basis for users to make decisions.

\section{5) System Management}

Being fundamental for system operation, this module mainly includes maintenance of public dictionary, maintenance of management system, user-defined configurations of work procedures [8], import of financial data, user maintenance, maintenance of organizations, and maintenance of data accesses. It provides powerful basic data support for upstream businesses.

\section{6) Tag Management}

In this module, 2D barcodes and tags are generated and printed according to information about accounts of asset and equipment by integration of barcode printers.

\section{7) Routine Management}

This module is mainly utilized for users' routine equipment management, including prompts of early warnings and prompts of businesses to be handled as well as information release, view and downloading.

\section{Interface Design}

This system can provide an unified internal and external interfaces. Among them, the internal interface should cover the other application systems, such as ERP, MMIS; At the same time, the interface is able to provide an unified interface protocols to meet docking with external systems, such as enterprise OA office system, to meet the demand of the enterprise departments at all levels of management. 


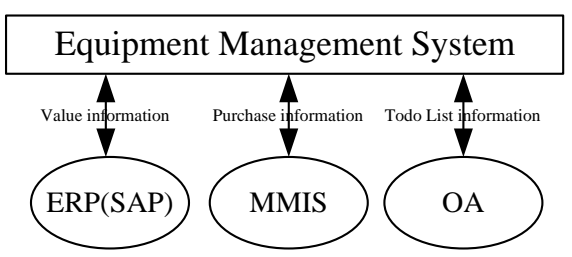

Figure 3. The interface desing

\section{Characteristics AND APPLICATIONS OF SYSTEM}

1. This system strengthens information traceability and management of equipment through the internet of things by barcodes and electronic RFID tags, etc.

2. It makes an inventory of equipment electronically with mobile internet applications by scanning for recognition through mobile handheld terminals. Inventory efficiency and accuracy are greatly increased.

3. Workflow engines are used for supporting flexible expansion and modification of enterprises' equipment management procedures, in order to be in line with practical equipment management of enterprises.

4. Means like electronic signatures are adopted to guarantee information security by preventing data fabrication, tampering and denial.

5. This system supports effective integration with ERP, management information system for railways and corporate
OA system. This fully reflects enterprises' concepts of intensive management and meets requirements of management departments at all levels for business integration and information sharing.

\section{REFERENCES}

[1] Wang Junqiang. Research and Implementation of Equipment Management Information System Based on Component [M]. Computer Integrated Manufacturing Systems, October 2004 (9).

[2] Qin Jianhua, Huang Shijie. Development of Equipment Management Information System [M]. Computer Applications, 2001, 21 (zl).

[3] Xiong Guanghua. Frame Design, Technical Implementation Pattern and Application of Equipment Information Management System [M] Journal of Wuhan Engineering Institute, 2007, 19 (1).

[4] Jia Xiuping, Zhang Guanghui, Meng Lili. Plant Management Information System Based on B/S Model [M]. Plant Maintenance Engineering, 2008 (9).

[5] Chai Yongsheng. Research on Equipment Management Information System [M]. Computer Engineering and Applications, 2014, 40 (12).

[6] Jiang Feipeng. Design and Implementation of Management Information System for EMU's Maintenance and Repair Equipment [M]. Railway Computer Application, 2011, 20 (2).

[7] Jiang Zhiqiang. Development and Application of Equipment Management Information System [D]. China Plant Engineering, Beijing, 2011.

[8] Wang Wei. Workflow-based Design of Equipment Management Information System [D]. Jiangsu Science \& Technology Information, $2014(20)$. 